\title{
Integrated Waste Management Strategy
}

\author{
S. Longo Golder Paste Technology Ltd, Canada \\ K. Clarke-Whistler Golder Associates Ltd, Canada \\ F. Palkovits Golder Paste Technology Ltd, Canada
}

\begin{abstract}
The mining operations conducted in Northern Ontario are generally considered to be among the richest deposits in the world. This extensive area includes multiple active mines, smelters, and refineries. A number of active waste dumps for tailings, slag, and waste rock also exist.

It has been recognised that if current market conditions continue, and if the new reserve estimations are accurate, mining in this area could potentially continue for an additional 50 years.

Operational difficulties for the organisations operating in this area arise from the fact that the mining operations are situated in some cases within the city limits and, in fact, also dominate a number of small communities around the mine sites.
\end{abstract}

These organisations face a number of increasing regulatory and social demands which are a driving force behind many of the operational changes taking place within the mining community today. Rapidly, an environmentally conscious mining operation is becoming the norm.

A solution to satisfying these escalating demands is the development and application of an integrated waste management strategy. Integrated waste management is a system in which the technical, environmental, social, economic, and risk aspects of the operation are studied. Following this a comparative analysis is conducted which balances the socio-economic benefits achieved with the organisation's overall operating strategy.

The integrated waste management strategy is ranked and scored using a 'base case' model. Multiple alternatives and suggestions are then made against established criteria in a number of categories. Sensitivity analyses are also established to determine the robustness of the trade-offs.

\section{Introduction}

Mining operations in Northern Ontario have been a mainstay of the local economy for more than 100 years. Historical operations had significant impacts on regional environmental quality. However, reclamation and rehabilitation activities over the past 20 years have revitalised much of the north. Mining is still a significant business in Northern Ontario, but the economic base has now been expanded to include government and academic institutions and a significant recreational and tourism component.

At the current demand for nickel, copper, etc., operations in Northern Ontario are likely to continue for at least another 50 years. Local mining companies are currently reviewing their operations to ensure that there is adequate space for management of wastes from current and future operations. Part of this review includes ensuring that process and depositional practices are in line with corporate environmental performance standards.

This paper will discuss how an understanding of sustainable development can be used to develop an integrated waste management strategy, the potential costs of such a strategy and the socio-economic benefits of its adoption. 


\section{Sustainability issues in the mining sector}

With the booming economies of China and India, world demand for metals is at an all time high. Yet, development of mineral properties has never been more difficult. Resistance to resource development occurs within communities in both developed and developing economies. This is based not only on the environmental, social and cultural costs associated with resource development, but also on the legacy issues.

Global consolidation of the mining sector has produced a number of global giants who hold within their portfolios both exploration and operating properties. The large multi-nationals, such as Vale Inco, Xstrata, Anglo American, Barrick, Rio Tinto and BHP are sensitive to reputational risk and are seeking ways to 'raise the bar' on mining standards. Many have developed global environmental and social performance standards that often go well beyond national regulations, and they are actively developing new technologies to reduce environmental and social impacts.

\section{$3 \quad$ Integrated waste management strategy}

This particular study was intended to consider and make recommendations for integrated waste management practices for a mining company in Northern Ontario through to the year 2050 which corresponds to the period of the revised Life of Mine Plan (LOMP). These additional 40+ years of mine, mill, smelter and tailings area life have necessitated a review of the current practices in those areas for a variety of reasons including capacity, closure considerations, environmental performance, etc.

The overall objectives of this strategy are to:

- Minimise and consolidate the surface footprint of the different areas (tailings, mine rock and slag).

- Reduce generation of acid rock drainage and metal mobilisation into the environment and thus the environmental impact.

- Improve long term stability of surface dams in the tailings area.

- Minimise operating expenses which, given the length of operating time, may be a more important factor than capital expenses.

- Improve mine productivity with quality engineered backfill (reduced cycle times, less dilution, less mine dewatering, improved safety, reduced binder, faster strength gain, reduced barricade costs).

- Providing long term economic and amenity benefit to local communities.

The overall study plan was to establish the existing conditions, identify the Base Cases along with two or three alternatives for tailings, mine rock, slag and mine backfill that should be considered for future operations. The preferred alternatives were selected by a group of representative stakeholders. The decisions were based on a sustainability framework that included the evaluation of technical considerations, environmental impacts, social acceptability, and economics.

In order to provide a baseline for comparison later on, a key parameter was establishing the Base Case. The overall Base Case is described below.

\subsection{Base Case}

To summarise, the technology and waste management practices moving forward were assumed in the Base Case to be the same as the current practices.

- The tailings area will increase in height with conventional slurry disposal using large perimeter dams in all disposal areas.

- Mine rock handling remains as today where some is deposited into exhausted Pits (e.g. Mine No. 1); some is deposited on surface with truck transport, while Mine No. 3 continues to place all of its mine rock underground.

- The smelter slag pile would continue to grow its footprint using standard rail transport lines. 
- The mine backfill Base Case consists of cemented hydraulic fill (CHF) with some development rock dumped into stopes.

The quantities of waste material to be handled is outlined in the below tables.

\subsection{Alternatives}

In the initial stage of each case, only the 'pure' alternatives were considered. 'Pure' in this context is taken to mean solutions that only involve the deposition and transportation of each particular material, i.e. tailings, mine rock, slag and mine backfill separately without integration consideration. Once the 'pure' alternatives were developed then integration considerations were explored.

These 'pure' alternatives are described in more detail below.

\subsubsection{Tailings management}

For the tailings management area (TMA), five alternate layouts were developed which varied according to the following characteristics: pyrrhotite storage (from both environmental and potential re-milling perspectives); dam construction and stability; and water management strategies.

The three process technology alternatives considered were: thickened tailings; paste; and filter cake.

\section{Table 1 Tailings management alternatives}

\begin{tabular}{llllll}
\hline & \multicolumn{5}{c}{ Process Technology Alternatives (Product Types) } \\
Deposition (Layout) Alternatives & Slurry & $\begin{array}{l}\text { Thickened } \\
\text { Tailings }\end{array}$ & $\begin{array}{l}\text { Paste } \\
\text { Tailings }\end{array}$ & $\begin{array}{l}\text { Filtered } \\
\text { Tailings }\end{array}$ \\
& & $\sqrt{ }$ & $\sqrt{ }$ & $\sqrt{ }$ & $\sqrt{ }$ \\
\hline \multicolumn{2}{l}{ Base Case } & $\sqrt{ }$ & $\sqrt{ }$ & $\sqrt{ }$ & $\sqrt{ }$ \\
1. & TMA Layout 1 & $\sqrt{ }$ & $\sqrt{ }$ & $\sqrt{ }$ & $\sqrt{ }$ \\
2. & TMA Layout 2 & $\sqrt{ }$ & $\sqrt{ }$ & $\sqrt{ }$ & $\sqrt{ }$ \\
3. & TMA Layout 3 & $\sqrt{ }$ & $\sqrt{ }$ & $\sqrt{ }$ & $\sqrt{ }$ \\
4. & TMA Layout 4 & $\sqrt{ }$ & $\sqrt{ }$ & $\sqrt{ }$ & $\sqrt{ }$ \\
5. & TMA Layout 5 & & & & \\
\hline
\end{tabular}

\subsubsection{Mine backfill}

The mine backfill considered two alternate backfill technologies namely: paste fill (PF); and cemented rock fill (CRF).

Table 2 Mine backfill management alternatives

\begin{tabular}{llll}
\hline \multirow{2}{*}{ Deposition (Location) Alternatives } & \multicolumn{3}{c}{ Process Alternatives } \\
& CHF (Base Case) & PF & CRF \\
\hline Alternative 1 - Disposal into Mine No. 1 & $\sqrt{ }$ & $\sqrt{ }$ & $\sqrt{ }$ \\
Alternative 2 - Disposal into Mine No. 2 & $\sqrt{ }$ & $\sqrt{ }$ & $\sqrt{ }$ \\
Alternative 3 - Disposal into Mine No. 3 & $\sqrt{ }$ & $\sqrt{ }$ & $\sqrt{ }$ \\
\hline
\end{tabular}




\subsubsection{Mine rock and slag}

For both mine rock and slag, multiple deposition locations and transportation technologies were considered. The deposition alternatives for both were as follows: disposal into exhausted pits; disposal into the TMA; disposal into backfill; and disposal through sale. The process transportation technologies were as follows: trucking; conveying; and rail transport. In both cases, the connection with thickened tailings or paste in a 'pure' context was non-existent.

\section{Table 3 Mine rock and slag management alternatives}

\section{Process Alternatives}

\begin{tabular}{lllll} 
Deposition Alternatives & Trucking & Conveying & Rail & Pumping \\
\hline Base Case & $\sqrt{ }$ & $\sqrt{ }$ & $\sqrt{ }$ & $\sqrt{ }$ \\
Alternative 1 - Disposal into TMA & $\sqrt{ }$ & $\sqrt{ }$ & $\sqrt{ }$ & $\sqrt{ }$ \\
Alternative 2 - Disposal into exhausted pits & $\sqrt{ }$ & $\sqrt{ }$ & $\sqrt{ }$ & $\sqrt{ }$ \\
Alternative 3 - Disposal into backfill & $\sqrt{ }$ & $\sqrt{ }$ & $\sqrt{ }$ & $\sqrt{ }$ \\
Alternative 4 - Disposal through sale & $\sqrt{ }$ & $\sqrt{ }$ & $\sqrt{ }$ & $\sqrt{ }$ \\
\hline
\end{tabular}

\subsubsection{Integration}

In the tailings and backfill area of consideration under the Base Case, thickened tailings and/or paste options came up as viable alternatives to conventional practices of disposal. While these two areas had the most significant presence of thickened tailings and/or paste options, in both the slag and mine rock areas, there was consideration given in how they would integrate with the solutions provided in the tailings and backfill areas. Some of these considerations are as follows:

- Co-disposal in the TMA as dam building material.

- Co-mingling for cover material.

- 'Aggregate' addition for backfill.

In each case, the alternatives were analysed in terms of technical, environmental, social, and economical criteria and that analysis and assessment was presented as background material for the stakeholders to use as points of discussion during the evaluation meetings.

\section{$4 \quad$ Sustainability appraisal}

A set of evaluation criteria were developed to assess the sustainability of the various alternatives (Table 4). These considered key technical, environmental, social, and economic elements of each alternative. The evaluation criteria were developed through a multi-stakeholder team that included representatives of the mining company's corporate and site operations, and a number of external technical experts. 
Table 4 Evaluation criteria based on technical, environmental, social and economic elements

\begin{tabular}{ll}
\hline Criteria & Scoring \\
\hline
\end{tabular}

\section{Technical}

\section{Dewatering and Transport}

Flexibility of system for dewatering different types of tailings

Design complexity of plant

Reliability of plant operation

Design complexity of transport systems

Reliability of transportation operations

Impact to other processes

\section{Stack and Dam Stability}

Design complexity

Reliability of operations

\section{Capacity}

Design complexity

Reliability of operations

Flexibility for future expansion
High level of flexibility $=5$

Low level of flexibility $=1$

Simple $=5$

Complex $=1$

High reliability $=5$

Low reliability $=1$

Simple $=5$

Complex $=1$

High reliability $=5$

Low reliability $=1$

Low impact $=5$

High impact $=1$

Simple $=5$

Complex $=1$

High reliability $=5$

Low reliability $=1$

Simple $=5$

Complex $=1$

High reliability $=5$

Low reliability $=1$

High flexibility $=5$

Low flexibility $=1$

\section{Environmental}

\section{Reactivity of Stack}

Design complexity

Simple $=5$

Complex $=1$

Reliability of operations

High reliability $=5$

Low reliability $=1$

\section{Cover System}

Design complexity

Simple $=5$

Complex $=1$

Reliability of operations

High reliability $=5$

Low reliability $=1$

\section{Receiving Environment}

Water quantity

Beneficial effect $=5$

Adverse impact $=1$ 


\begin{tabular}{ll}
\hline Criteria & Scoring \\
\hline Water quality - groundwater & Beneficial effect $=5$ \\
& Adverse impact $=1$ \\
Water quality - surface water & Beneficial effect $=5$ \\
Air quality & Adverse impact $=1$ \\
& Beneficial effect $=5$ \\
Terrestrial and aquatic ecosystems & Adverse impact $=1$ \\
& Beneficial effect $=5$ \\
Potential for small scale spills & Adverse impact $=1$ \\
& Low potential $=5$ \\
\hline
\end{tabular}

\section{Social}

\section{Human Environment}

Worker health and safety

Low risk $=5$

High risk $=1$

Community health and safety

Low risk $=5$

High risk $=1$

Aesthetics

Low risk $=5$

High risk $=1$

Impacts to hunting, fishing and recreational use

Low risk $=5$

High risk $=1$

Transportation and infrastructure

Low impact $=5$

High impact $=5$

Direct and indirect socio-economic impact

High benefit $=5$

Adverse impact $=1$

Value of end land use

High potential $=5$

Low potential $=1$

Public acceptance

High $=5$

Low $=1$

Technology development and industry leadership (innovation)

High potential $=5$

Low potential $=1$

\section{Economic}

Capital cost

Low cost $=5$

High cost $=1$

Operating cost

Low cost $=5$

High cost $=1$

Distribution of cost over time

Long distribution $=5$

Short distribution $=1$

Closure cost

Low cost $=5$

High cost $=1$

Pyrrhotite recovery

Easiest $=5$

Hardest $=1$

Overall project level of confidence

High $=5$

Low $=1$ 
The evaluation procedure included the following:

- Each element (technical, environmental, social, financial) was assigned a weighting out of 100 by the stakeholders.

- Within each element, each criterion was assigned a weighting out of 100 by the stakeholders.

- Each criterion was scored based on 1 (least favourable) to 5 (most favourable).

- Each alternative was then scored.

The weighting of the elements (technical, environmental, social and economic) varied depending on the waste component being considered. Table 5 shows the weightings.

Table 5 Weightings used in sustainability appraisal

\begin{tabular}{lllll}
\hline & & Weightings (\%) & \\
Element & Tailings & Mine Rock & Slag & Backfill \\
\hline Technical & 37 & 10 & 15 & 40 \\
Environmental & 21 & 35 & 25 & 15 \\
Social & 8 & 25 & 25 & 15 \\
Economic & 34 & 35 & 35 & 30 \\
\hline
\end{tabular}

The higher weighting for the technical element in evaluation of the backfill alternatives reflects the greater level of technical uncertainty.

\section{$5 \quad$ Results}

Based on the assessments and data presented, waste management alternatives were discussed and reviewed in terms of their strengths, weaknesses, opportunities and threats (SWOT) in meetings. In the first two SWOT meetings, the Base Cases were compared against the alternatives for tailings, mine rock, slag and mine backfill. In all cases, alternatives were assessed relative to their respective Base Cases using technical, environmental, social and economic criteria. The following conclusions and preferred alternatives were reached.

\subsection{Tailings}

The Base Case was found to be the least preferred deposition layout alternative for tailings while deposition layouts Alternative 2 and Alternative 5 were the most preferred. In terms of process technologies, thickened tailings emerged as the most preferred. The current slurry technology was considered the least preferred, largely the result of environmental considerations.

\subsection{Mine rock}

As with tailings, the Base Case was found to be the least preferred option while disposal into exhausted pits rated as the most preferred alternative followed closely by disposal into the TMA. Trucking was the preferred means of transportation of the mine rock waste stream.

\subsection{Slag}

When considering the disposal of slag, disposal of this material into the TMA was the most preferred alternative followed by in-pit disposal. The Base Case was considered the least favourable alternative. Rail was the preferred transport option. 


\section{$5.4 \quad$ Mine backfill}

The results clearly indicated a strong preference towards using PF as mine backfill in comparison to CRF, which was the least preferred alternative.

\subsection{Sensitivity analysis}

The analysis in all cases produced consistent results, even when technical, environmental, social and economic elements were varied. In order to ensure that the integrated solution(s) (comprised of the preferred selected alternatives from the SWOT meetings) are robust, several strategic themes were proposed as ways to compare and evaluate the solution(s). This evaluation served to confirm that a) the correct alternatives were selected; and b) that the integrated solutions met the needs of the company as indicated by the design drivers.

The strategic themes were as follows:

- Strategy 1: Base Case solution for all materials.

- Strategy 2: Most environmental and socially proactive solution.

- Strategy 3: Most economic solution that is not the Base Case.

- Strategy 4: Most risk minimising solution (corporate reputation and technical/stability perspective).

- Strategy 5: Highest scoring alternatives solution (taking all the "best" scores from each SWOT and combining into one solution).

Table 6 Sensitivity analysis of strategic themes

\begin{tabular}{|c|c|c|c|c|c|c|}
\hline Strategy & & $\begin{array}{l}\text { Base } \\
\text { Case }\end{array}$ & $\begin{array}{l}\text { Most } \\
\text { Environmental } \\
\text { and Socially } \\
\text { Proactive } \\
\text { Solution }\end{array}$ & $\begin{array}{l}\text { Most } \\
\text { Economic } \\
\text { Solution that } \\
\text { is not the } \\
\text { Base Case }\end{array}$ & $\begin{array}{l}\text { Most Risk } \\
\text { Minimising } \\
\text { Solution } \\
\text { (Technical) }\end{array}$ & $\begin{array}{l}\text { Highest } \\
\text { Scoring } \\
\text { Alternatives } \\
\text { Solution }\end{array}$ \\
\hline \multirow[t]{2}{*}{ Tailings } & Location & $\mathrm{R}$ area & Alternative 5 & Alternative 2 & Alternative 2 & Alternative 2 \\
\hline & Process & Slurry & $\begin{array}{l}\text { Thickened or } \\
\text { paste }\end{array}$ & Thickened & Filter cake & Thickened \\
\hline \multirow{2}{*}{$\begin{array}{l}\text { Mine } \\
\text { Rock }\end{array}$} & Location & Surface & Pits/backfill & Pits & Pits & Pits \\
\hline & Process & Truck & Conveyor & Truck & Truck & Truck \\
\hline \multirow[t]{2}{*}{ Slag } & Location & TMA & TMA or pits & Pits & TMA & TMA \\
\hline & Process & Rail & Rail/conveyor & Rail & Truck & Rail \\
\hline Backfill & Process & $\mathrm{CHF}$ & Paste backfill & Paste backfill & Paste backfill & Paste backfill \\
\hline
\end{tabular}

\section{Cost versus benefit}

As can be seen in the weightings of criteria, economics was consistently the most heavily weighted of all the criteria although it is interesting to note that combined environmental and social considerations outranked economics in most cases.

To summarise the cost versus benefits for each material, mine rock and slag alternatives when costed (capex and opex) were essentially equivalent (minimal increase) to the base case scenario so economically speaking there was no advantage of the alternatives over the base case. For mine rock and slag the biggest area of improvement would be in the environmental and social aspects i.e. reduction of acid generation and dusting issues as well as some technical improvements in cycle time which were difficult to quantify at this level of study. 
The significant cost savings and/or gains are made in the tailings and mine backfill areas which coincidentally are the areas taking most advantage of the thickened tailings and paste alternatives. For the tailings, as expected the capital expense of moving to thickened tailings processing from conventional slurry deposition represented an increase of $47 \%$ (capex) but when offset by synergies that could be gained with multiple thickening plants and the reduction in future dam raises in the TMA the increase in costs was reduced. Also of extreme benefit is the reduction of seepage and acid generation through the tailings stack which reduces the long term load on the water treatment facilities. This would also represent a cost savings to the overall process not to mention the added benefit to the environment which again is difficult to quantify.

For mine backfill, the expected increase in productivity and the reduction of dilution costs from switching to paste backfill represents actual generation of revenue, this coupled with the decrease in cycle time (reduction in operating costs by up to $40 \%$ ) and synergies with the thickened tailings processing plants means for this particular example the "extra" capital required for the tailings area is more than covered by the gains made on the mining cycle. Broken down below are the capital and operating costs.

Table 7 Capital and operating costs of strategic alternatives

\begin{tabular}{|c|c|c|c|c|}
\hline $\begin{array}{l}\text { Strategic } \\
\text { Alternatives }\end{array}$ & $\begin{array}{l}\text { Base Case (Tailings, } \\
\text { and Mine Backfill) }\end{array}$ & Mine Rock, Slag & $\begin{array}{l}\text { Thickened Tailings De } \\
\text { Rock in the Pits/Slag in } \\
\text { in the Pits + Paste Back }\end{array}$ & $\begin{array}{l}\text { osition + Mine } \\
\text { the CTA/Slag } \\
\text { fill }\end{array}$ \\
\hline $\begin{array}{l}\text { Principal Design } \\
\text { Drivers }\end{array}$ & $\begin{array}{l}\text { Strength/ } \\
\text { Opportunity }\end{array}$ & $\begin{array}{l}\text { Weakness/ } \\
\text { Threat }\end{array}$ & Strength/Opportunity & $\begin{array}{l}\text { Weakness/ } \\
\text { Threat }\end{array}$ \\
\hline $\begin{array}{l}\text { NPV capital and } \\
\text { operating costs }\end{array}$ & $\begin{array}{l}\text { Capex (\$M NPV) / } \\
\text { Opex (\$M NPV / unit } \\
\text { rate Opex }\end{array}$ & & $\begin{array}{l}\text { Capex (\$M NPV) / Opex } \\
\text { (\$M NPV) / unit rate } \\
\text { Opex }\end{array}$ & \\
\hline Tailings & $68 / 103 / 0.89 \mathrm{pt}$ & & $\begin{array}{l}146 / 103 / 8.50 \text { py } \\
(20 \text { yrs })\end{array}$ & \\
\hline Mine rock & $\sim \$ 1.10$ per ton & & $\$ 1.10-\$ 2.10 /$ ton & \\
\hline Slag & $0 / 43 / 2.10 \mathrm{pt}$ & & & \\
\hline $\begin{array}{l}\text { CTA } \\
\text { Pits }\end{array}$ & & & $\begin{array}{l}0 / 57.3 / 2.80 \mathrm{pt} \\
0 / 51.2 / 2.50 \mathrm{pt}\end{array}$ & \\
\hline $\begin{array}{l}\text { Mine backfill } \\
\text { Mine No. } 1 \\
\text { Mine No. } 2 \\
\text { Mine No. } 3\end{array}$ & $\begin{array}{l}0 / 112 / 18.50 \\
0 / 185 / 13.00 \\
0 / 47 / 9.50\end{array}$ & & $\begin{array}{l}25 / 52 / 8.50 \\
24 / 107 / 7.20 \\
19 / 49 / 7.20\end{array}$ & \\
\hline
\end{tabular}

In Table 7, the capital and operating costs consider that which is easily quantifiable at this level of study. Most of the environmental and social impacts are difficult to quantify but in the SWOT discussions significant time was spent discussing sustainability and the best available techniques for dealing with waste streams. During these discussions it became clear that even without some costs (or gains) being quantifiable ignoring the environmental and social impacts would eventually have impacts on the social license to operate of this company.

\section{Conclusions}

Broadly speaking this study has shown that there is compelling rationale for assessing the sustainability and integratability of multiple waste stream deposition. Historically, each of these waste streams disposal systems would have been designed independently however with these waste materials being highly interrelated there are opportunities to consider them together to arrive at one integrated design. As independent operating groups it doesn't make economic sense for some operations to invest capital for which they will see only indirect improvements or efficiency gains. 
However, if the idea of sustainability and integration becomes part of the equation (which essentially brings the environmental and social aspects to bear) then the efficiencies are gained and disadvantages are minimised across the operation as a whole which will have a bottom and top line impact.

\section{Acknowledgements}

The authors would like to thank the management team of the mining company who provided the forum for this study as well as the team who worked on this integrated waste management strategy. 